\title{
Public perception of an approach to achieve the goals of climate change policies
}

\author{
M. Pletikosić \\ Cemex, Croatia
}

\begin{abstract}
This paper interprets the results of the empirical research on the awareness and the opinions of the interested public about the usage of fuel made from waste as an alternative fuel in the cement industry in Croatia. The fossil fuels have created the modern economy in which the emissions of the carbon dioxide represent an immense threat to the environment. To achieve these high set goals it is necessary to make great efforts in informing and sensitizing the public. The research was conducted on the aim sample by an in-depth interview method and by participating observance. The qualitative method of grounded theory was used in the analysis of the empirical material. The coded material was quantitatively processed and calculated with the help of the STATISTICA Ver 11.00 statistic package. The aim of the research was to determine the awareness and the opinions of the interested public about the reasons for the substitution of fossil fuels with alternative fuels made of waste in the cement factory, as well as their influence on climate change. The research determined the level of awareness of the aim and sector groups, related to substitute fuels in industry as an adaptation in the fight against climate change. Most of the examinees considered that the reason for the usage of fuels made of waste in cement factories was finances and they did not directly relate the substitution of the fossil fuels to the adjustment to climate change and the decrease of carbon dioxide emission. Most of the examinees were not sure if the fossil fuels or fuels made of waste were a better solution for the climate change problem. They mostly expressed an opinion that the usage of fuels made of waste in the cement factories was allowed by Croatian laws.

The result analysis showed that the representatives of the aim and sector groups differed in the used variables, depending on the group they belonged to. Keywords: public opinions, alternative fuels, carbon dioxide emission.
\end{abstract}




\section{Introduction}

Mitigation and adjustment to climate change is one of the main global aims and challenges for contemporary governments and their responsibility in the sustainable development of economy and society. Since three quarters of greenhouse gases increase is caused by carbon dioxide, our greatest priority of reduction should be decrease of $\mathrm{CO}_{2}$ emission. Most of the $\mathrm{CO}_{2}$ emissions are caused by burning the fossil fuels, which is why the reduction of $\mathrm{CO}_{2}$ energy emissions presents one of the priorities. The uncontrolled deforestation and changes in land usage, methane emissions and nitrogen oxides present the rest, or one quarter of anthropogenic greenhouse gases. The switch to the energy system with low carbon share demands new technologic alternatives in using the new energy sources and achieving the reduction of greenhouse gases using the most profitable methods. One of the most significant challenges is decarbonisation of the economy, by high decrease of carbon dioxide and fossil fuels usage, what should be realised by increasing the energy efficiency through increased production per unit of energy intake, as well as using the energy from the renewable sources, without the harmful emissions, such as wind, sun, geothermal energy, hydropower plants, biomass and different kinds of substitution fuels of non-fossil origin (Battelle [1]). A significant place belongs to the establishment of the waste management system through the decrease of amount of waste at the place of origin, primary selection and sorting, recycling and especially material and energy recovery. By signing the Treaty of Croatia's Accession to the European Union the Republic of Croatia committed to fulfil the aims for certain areas such as waste management and the decrease of the greenhouse gases emission. According to the Treaty of Croatia's Accession to the European Union, all the existing landfills in Croatia will have to fulfil the demands of the Directive on the landfill of waste by December $31^{\text {st }} 2018$. The cement industry can significantly contribute to the realisation of this goal because the European experiences show that 1 ton of communal and similar waste gives about $400 \mathrm{~kg}$ of fuel (RDF/SRF), and that is also the amount that would not have to be sent to the landfills. Deposal is accepted only as the last solution in the waste management hierarchy. The more waste recycled or recovered, materially or energetically, means less communal waste in landfills. Material and energetic recovery takes a significant place in waste management. Besides the Accession Treaty, the Republic of Croatia is obliged to follow the Kyoto protocol and the document known as Europe 2020. In this document, the European goals up to year 2020 connected to climate change/energy are listed and elaborated: decrease of greenhouse gases emission by $20 \%$, increase of the share of renewable energy sources by $20 \%$ in the immediate energy consumption, improvement of energy efficiency by $20 \%$. The co-incineration in cement plants substitutes' part of the fossil - non-renewable fuels, with fuel made from waste, significantly decreasing the emission of carbon dioxide from the process of clinker production. To achieve such high set goals it is necessary to invest great efforts in informing and sensitizing the public. The aim of the research was to determine the degree of awareness and the attitudes of 
the interested public on the reasons for the substitution of fossil fuels with fuels obtained from waste in cement plants and their influence on climate change. The research determined the degree of awareness of aim and sector groups related to the substitution fuels in industry as an adjustment in the fight against climate change.

\section{Methods}

The sample of examinees was defined by 100 entities, 55 male and 45 female. Mean age of examinees was 47.9 years. Examinees' age, education level, employment status and place of residence are shown in Table 1.

Table 1: Demographic sample structure.

\begin{tabular}{|c|c|c|c|}
\hline \multirow{2}{*}{\multicolumn{2}{|c|}{ Total sample }} & $\mathrm{N}$ & $\%$ \\
\hline & & 100 & $100 \%$ \\
\hline \multirow{2}{*}{ Gender } & Male & 55 & $55 \%$ \\
\hline & Female & 45 & $45 \%$ \\
\hline \multirow{4}{*}{ Age } & Under 30 & 3 & $3 \%$ \\
\hline & Between 31 and 44 & 22 & $22 \%$ \\
\hline & Between 45 and 60 & 62 & $62 \%$ \\
\hline & Over 60 & 13 & $13 \%$ \\
\hline \multirow{2}{*}{ Education } & High school & 28 & $28 \%$ \\
\hline & Undergraduate/Graduate & 72 & $72 \%$ \\
\hline \multirow{4}{*}{$\begin{array}{l}\text { Employment } \\
\text { status }\end{array}$} & Unemployed & 7 & $7 \%$ \\
\hline & Employed & 82 & $82 \%$ \\
\hline & Retired & 6 & $6 \%$ \\
\hline & Students & 5 & $5 \%$ \\
\hline \multirow{3}{*}{ Town } & Kaštela & 39 & $39 \%$ \\
\hline & Solin & 36 & $36 \%$ \\
\hline & Split & 25 & $25 \%$ \\
\hline
\end{tabular}

Legend: $\mathrm{N}$ - number of examinees; \% - relative values.

The examinees were divided into nine subsamples (target groups) which were qualitatively defined: ORGANIZATIONS - representatives of non-governmental environmental organizations of Split-Dalmatia County, 10 subjects; TOWNS representatives of local government employees from Kaštela, Solin and Split, 10 subjects; BUYERS/SUPPLIERS - representatives of buyers and suppliers of CEMEX Croatia, 10 subjects; POLITICS/SCIENCE - representatives of local political structures and scientists, 10 subjects; SPONSORSHIP AND DONATIONS RECIPIENTS - representatives of beneficiaries and recipients of CEMEX sponsorships and donations, 10 subjects; KAŠTELA RESIDENTS representatives of neighbours of the plant "Sv. Juraj" in Kaštel Sućurac, 15 subjects; SOLIN RESIDENTS - representatives of neighbours of the plant "Sv. Kajo" in Solin, 15 subjects; CEMEX EMPLOYEES - representatives of CEMEX employees, 10 subjects; COUNTY - representatives of local government employees of Split-Dalmatia County, 10 subjects. 
Out of the abovementioned subsamples, three new clusters (sectors) consisting of the total of 70 subjects were classified, which were qualitatively defined as:

PUBLIC SECTOR - 30 subjects from the target groups: TOWNS, POLITICS/SCIENCE and COUNTY.

CIVIL SECTOR - 20 subjects from the target groups: ORGANIZATIONS and SPONSORSHIP AND DONATIONS RECIPIENTS.

ECONOMIC SECTOR - 20 subjects from the target groups:

BUYERS/SUPPLIERS and CEMEX EMPLOYEES.

The sample of variables was represented by a group of 3 qualitatively defined questions used in open and/or indirect interview.

The first variable with a code name substitution announcement fossil fuels fuels made from waste was defined based on the first question:

1. Why did the cement plant announce the substitution of fossil fuels with fuels made from waste?

The second variable with a code name Croatian law using the fuels made from waste in cement plants was defined based on the $2^{\text {nd }}$ question:

2. Does the Croatian law allow usage of fuels made from waste in cement plants?

The third variable with a code name fossil fuels $R D F$ solving the problem of climate change was defined based on the $3^{\text {rd }}$ question:

3. In your opinion, are fossil fuels or fuels made from waste better at solving the problem of climate change?

A problem-oriented in-depth interview was conducted with 100 subjects divided into nine target groups and three control sector groups, representing a target sample of the interested public which is rich in information and, in its activity, involved in forming the attitudes of others.

After being presented with the problem and the target of the research, all subjects gave a willing consent for participation in the research.

Based on written transcripts, the numerical coding of responses was performed, with the aim of forming the entity matrix, defined by the overall subject sample and coded variables, for further statistical analysis. The descriptive analysis determined the frequency of every applied variable with code names, as well as their relative values (Charmaz [2]).

Quantification of qualitative empiric material and transformation to the numerical form was performed for the purposes of further statistical analysis. Complete statistical analysis was performed by STATISTICA, Ver.10.00 software package.

\section{Results and discussion}

In answering the first question the examinees expressed their attitude and opinion on reasons for introduction of fuels made from waste as a substitution for fossil fuels. The answers of the examinees were defined in three levels: The first group represented those entities who gave the following answers: the legal obligations, also comprising the decrease of greenhouse gases, $\mathrm{CO}_{2}$, waste 
management, Kyoto protocol etc., were the reasons for introduction of fuels made from waste as a substitution for fossil fuels. Quantitatively, these answers were coded by number 1 (one), because of the forthcoming statistical data processing. The second group defined their answers as: introduction of the fuels made from waste as a substitution for fossil fuels was conditioned exclusively by profit, financial reasons and decrease of production expenses. Quantitatively, these answers were coded by number 2 (two).

The third group of examinees was classified according to answers: The reasons for introduction of fuels made from waste as a substitution for fossil fuels are multiple. It was partly conditioned by profit, financial reasons and the decrease of the production expenses and partly by legal obligations, need for the decrease of greenhouse gases, $\mathrm{CO}_{2}$, waste management, Kyoto protocol etc. Quantitatively, these answers were coded by number 3 (three).

The descriptive analysis of the first variable with code name substitution announcement_fossil fuels_fuels made from waste determined the frequency of quantitative answers of the total sample, followed by nine aim groups that were redefined in the process of analysis as three new sectors. The analysis and statistical processing for all the classified subsamples was performed as well.

The analysis of frequency results of all the examinees and the $1^{\text {st }}$ variable with code name substitution announcement_fossil fuels_fuels made from waste showed the relative value of $57 \%$ entities with an attitude that the introduction of fuel made from waste as a substitute for fossil fuels, was conditioned exclusively by profit, financial reasons and decrease of production expenses

The relative value of $21 \%$ belonged to examinees who had an attitude and considered that the legal obligations, comprising the Kyoto protocol, decrease of greenhouse gases, $\mathrm{CO}_{2}$, waste management, etc., were the reason for introduction of fuels made from waste as a substitute for fossil fuels. The remaining part of the examinees, numerically defined with a relative value of $22 \%$, included the entities who considered that the reason for the usage of substitution fuels were multiple, comprising the financial decrease of expenses, profit, but also the legal obligations, Kyoto protocol, decrease of greenhouse gases and $\mathrm{CO}_{2}$.

Table 2 shows the results of total number of entities frequency and the $1^{\text {st }}$ variable substitution announcement_fossil fuels_fuels made from waste frequency.

Table 2: Frequencies and relative values of substitution announcement_fossilfuels_fuels made from waste variable, $\mathrm{N}=100$.

\begin{tabular}{|c|c|c|}
\hline & Freq & $\%$ \\
\hline 1 & 21 & 21.00 \\
\hline 2 & 57 & 57.00 \\
\hline 3 & 22 & 22.00 \\
\hline Total & 100 & 100.00 \\
\hline
\end{tabular}

Legend: 1 - legal obligations; 2 - financial reasons; 3 - legal obligations and financial reasons. 
The table representation (table 3) of the substitution announcement fossil fuels fuels made from waste variable, and the aim group grouping variable, indicated that the subsamples differed in the defined answers. Namely, the representatives of the REC.SPO/DON, EMP/CEM and COU listed the decrease of expenses or profit as the least important reason for substitute of fossil fuels with fuels made from waste. The examinees of COU aim group, with the $9 \%$ share in the total sample, were of the opinion that reason for introduction of substitute fuels was mostly conditioned by the legal standards and the needs of greenhouse gases decrease. The representatives of EMP/CEM mostly expressed the opinion that the reason for the substitute was a mutual need comprising the decrease of expenses and the fulfilment of legal standards. All the other defined aim groups, with the total relative value of $57 \%$, considered that the exclusive reason for introduction of substitute fuels made from waste instead of fossil fuels, was financially conditioned, with the aim of decreasing the production expenses of the cement plants and the profit increase.

Table 3: The frequency of substitution announcement_fossil fuels_fuels made from waste variable, according to aim group, $\mathrm{N}=100$.

\begin{tabular}{|l|c|c|c|c|c|c|c|c|c|c|}
\hline & ORG & CIT & $\begin{array}{c}\text { BUY/ } \\
\text { SUPP }\end{array}$ & $\begin{array}{c}\text { POL/ } \\
\text { SCI }\end{array}$ & $\begin{array}{c}\text { REC.SPO/ } \\
\text { DON }\end{array}$ & $\begin{array}{c}\text { RES/ } \\
\text { KAŠ }\end{array}$ & $\begin{array}{c}\text { RES/ } \\
\text { SOL }\end{array}$ & $\begin{array}{c}\text { EMP/ } \\
\text { CEM }\end{array}$ & COU & TOTAL \\
\hline 1 & 0 & 0 & 0 & 2 & 4 & 2 & 0 & 4 & 9 & 21 \\
\hline 2 & 8 & 7 & 9 & 8 & 3 & 13 & 9 & 0 & 0 & 57 \\
\hline 3 & 2 & 3 & 1 & 0 & 3 & 0 & 6 & 6 & 1 & 22 \\
\hline TOTAL & 10 & 10 & 10 & 10 & 10 & 15 & 15 & 10 & 10 & 100 \\
\hline
\end{tabular}

Legend: 1 - legal obligations; 2 - financial reasons; 3 - legal obligations and financial reasons.

Analysis 1 of the variable with the code name substitution announcement_fossil fuels fuels made from waste according to the sector group confirmed that the examinees within the defined clusters differed in opinion which was the main reason of using the fuels made from waste instead of fossil fuels in cement plants. The entire sector groups mostly expressed the attitude that the reasons for usage of fuels made from waste were decrease of production expenses and profit, with total part of 35 entities or 50\%. Also, 19 examinees in all the sectors, or $34 \%$ of the total sample, listed the reasons for substitution of fuels: waste management, decrease of greenhouse gases, Kyoto protocol, legal regulations and ecological normative. The remaining $26 \%$ of sector group representatives, or 16 entities, listed both reasons for introduction of substitution fuels. All the listed quantitative values are displayed in table 4.

In answering the second question the examinees expressed their attitude and knowledge of Croatian laws which regulated the usage of fuels made from waste in cement plants.

The answers of the examinees were defined in four levels: The first group classified those entities who answered negatively: Croatian law does not allow the usage of fuels made from waste in cement plants. Quantitatively, these 
Table 4: The frequency of substitution announcement_fossil fuels_fuels made from waste variable according to the sector group, $\mathrm{N}=70$.

\begin{tabular}{|l|c|c|c|c|c|c|c|c|c|c|}
\hline & ORG & CIT & $\begin{array}{c}\text { BUY/S } \\
\text { UP }\end{array}$ & $\begin{array}{c}\text { POL/S } \\
\text { CI }\end{array}$ & $\begin{array}{c}\text { REC.SPO/DO } \\
\text { N }\end{array}$ & $\begin{array}{c}\text { RES/K } \\
\text { AS }\end{array}$ & $\begin{array}{c}\text { RES/S } \\
\text { OL }\end{array}$ & $\begin{array}{c}\text { RES/C } \\
\text { EM }\end{array}$ & COU & TOTAL \\
\hline 1 & 0 & 0 & 0 & 2 & 4 & 2 & 0 & 4 & 9 & 21 \\
\hline 2 & 8 & 7 & 9 & 8 & 3 & 13 & 9 & 0 & 0 & 57 \\
\hline 3 & 2 & 3 & 1 & 0 & 3 & 0 & 6 & 6 & 1 & 22 \\
\hline TOTAL & 10 & 10 & 10 & 10 & 10 & 15 & 15 & 10 & 10 & 100 \\
\hline
\end{tabular}

Legend: 1 - legal obligations; 2 - financial reasons; 3 - legal obligations and financial reasons.

results were coded by number zero (0), due to the forthcoming statistic data processing.

The second group defined their answer in a positive way: Yes, Croatian law allows the usage of fuels made from waste in cement plants. Quantitatively, these answers were coded by number 1 (one).

The third group remained undefined and was classified according to the answer: I don't know, I'm not sure, I'm not well informed, I don't know the facts and I can't answer etc. Quantitatively, these incomplete answers were coded by number 2 (two).

The fourth group of examinees was defined according to the answer: The CEMEX cement plant has just applied for the fuel usage licence. Quantitatively, these answers were coded by number 3 (three).

The name of the answer to the second question was defined in the statistic processing by a variable with a code name: Croatian law_using the fuels made from waste in cement plants.

The descriptive analysis determined the frequency of coded answers for the total sample, nine aim groups that were redefined in the analysis process as three new sectors. Analysis and statistical processing had been performed for all the classified subgroups.

Table 5 shows the frequency results, as well as relative and cumulative values of all the entities and the $19^{\text {th }}$ variable Croatian law using the fuels made from waste in cement plants.

The examinees who were quantitatively defined by a relative value of $66 \%$ considered that the Croatian law allowed the usage of fuels made from waste in cement plants. $28 \%$ of entities was not sure, did not know, was not well informed and had no attitude on this question. The remaining relative value of $6 \%$ defined the examinees who believed that using the fuels made from waste was not legally regulated and comprised $3 \%$ of entities, and the remaining $3 \%$ of the sample was familiar with the fact that CEMEX was currently in the process of obtaining the licence for usage of fuels made from waste in their cement plants.

Table 6 shows the frequency results of the Croatian law using the fuels made from waste in cement plants variable, according to the aim group.

The representatives of the REC.SPO/DON, EMP/CEM and COU aim groups, unanimously claimed that the Croatian law allowed the usage of fuels made from 
Table 5: Relative and cumulative frequencies of the Croatian law_using the fuels made from waste in cement plants variable, $\mathrm{N}=100$.

\begin{tabular}{|c|c|c|}
\hline & Freq & $\%$ \\
\hline 0 & 3 & 3.00 \\
\hline 1 & 66 & 66.00 \\
\hline 2 & 28 & 28.00 \\
\hline 3 & 3 & 3.00 \\
\hline Total & 100 & 100.00 \\
\hline
\end{tabular}

Legend: 0 - no; 1 - yes; 2 - I don't know, I'm not sure, I'm partially informed, I don't have an attitude; 3 - the procedure of obtaining the usage licence.

waste in cement plants because all the examinees in the defined aim groups offered an identical answer. The $O R G, R E S / K A \check{S}$ and $R E S / S O L$ entities mostly had the same attitude, and the total number of the affirmative answers was quantitatively explained with 66 examinees. Nine out of ten CIT representatives were least informed, were not familiar with Croatian laws and did not know if the cement plants were allowed to use substitute fuels made from waste in cement plants. Three $P O L / S C I$ entities were familiar with the fact that CEMEX was currently in the process of obtaining the licence for RDF fuels usage in cement plants.

Table 6: The frequency of Croatian law using the fuels made from waste in cement plants variable, according to the aim group, $\mathrm{N}=100$.

\begin{tabular}{|l|c|c|c|c|c|c|c|c|c|c|}
\hline & ORG & CIT & $\begin{array}{c}\text { BUY/ } \\
\text { SUP }\end{array}$ & $\begin{array}{c}\text { POL/ } \\
\text { SCI }\end{array}$ & $\begin{array}{c}\text { REC.SPO/ } \\
\text { DON }\end{array}$ & $\begin{array}{c}\text { RES/ } \\
\text { KAŠ }\end{array}$ & $\begin{array}{c}\text { RES/ } \\
\text { SOL }\end{array}$ & $\begin{array}{c}\text { EMP/ } \\
\text { CEM }\end{array}$ & COU & TOTAL \\
\hline 0 & 0 & 1 & 0 & 2 & 0 & 0 & 0 & 0 & 0 & 3 \\
\hline 1 & 7 & 0 & 5 & 5 & 10 & 8 & 11 & 10 & 10 & 66 \\
\hline 2 & 3 & 9 & 5 & 0 & 0 & 7 & 4 & 0 & 0 & 28 \\
\hline 3 & 0 & 0 & 0 & 3 & 0 & 0 & 0 & 0 & 0 & 3 \\
\hline TOTAL & 10 & 10 & 10 & 10 & 10 & 15 & 15 & 10 & 10 & 100 \\
\hline
\end{tabular}

Legend: 0 - no; 1 -yes; 2 - I don't know, I'm not sure, I'm partially informed, I don't have an attitude; 3 - the procedure of obtaining the usage licence.

All the sectors were mostly of opinion (47 entities or $66 \%$ ) that the Croatian law allowed the usage of fuels made form waste in cement plants. The representatives of the public sector were least informed, had little information but were the only ones acquainted with the fact that CEMEX was currently in the process of obtaining the licence for usage of fuels made from waste in cement plants. All the results are shown in table 7. 
Table 7: The frequency of Croatian law_using the fuels made from waste in cement plants variable, according to the sector group, $\mathrm{N}=70$.

\begin{tabular}{|l|c|c|c|c|}
\hline & PUBLIC & CIVIL & ECONOMY & TOTAL \\
\hline 0 & 3 & 0 & 0 & 3 \\
\hline 1 & 15 & 17 & 15 & 47 \\
\hline 2 & 9 & 3 & 5 & 17 \\
\hline 3 & 3 & 0 & 0 & 3 \\
\hline TOTAL & 30 & 20 & 20 & 70 \\
\hline
\end{tabular}

Legend: 0 - no; 1 -yes; 2 - I don't know, I'm not sure, I'm partially informed, I don't have an attitude; 3 - the procedure of obtaining the usage licence.

In answering the third question, the examinees expressed their opinion on the question which fuels had greater influence on climate change: fossil fuels of fuels made from waste.

Four levels of answers were defined in the following manner: the examinees who answered that they did not know, were not sure, had little information or were partially acquainted were presented with number zero (0) due to the forthcoming statistical data processing.

The examinees who believed that the RDF fuels were more acceptable for usage in cement plants and that they influenced climate change less were quantitatively defined by number one (1).

The entities that were of opinion that the fossil fuels were less harmful for the environment and that they influenced climate change less were defined by an answer that was coded by number two (2). The entities that were of opinion that gas was the most acceptable for the environment and that it had least influence on climate change were defined by the answer that was coded by number three (3).

The entities who defined their answers: fossil fuels and fuels made from waste equally influenced climate change, both are harmful etc., were quantitatively coded by number four (4) due to the forthcoming statistical analysis.

The third variable had the code name: fossil fuels_RDF_solving the problem of climate changes.

The descriptive analysis determined the frequency of the quantitative answers for the total sample, nine aim groups which were redefined in the analysis process as three new sectors. The analysis and statistical processing of all the classified subgroups was performed as well.

The frequency results analysis for all the examinees and the $3^{\text {rd }}$ variable with a code name fossil fuels_RDF_solving the problem of climate changes was defined by a relative value of $26 \%$. The entities who preferred fossil fuels represented the $13 \%$ part, while $9 \%$ of examinees chose gas as the most acceptable option. $12 \%$ of the total sample considered that the fossil and RDF fuels were equally harmful for the environment. 
Table 8 shows the frequency results for all the entities and the variable with the code name fossil fuels_RDF_solving the problem of climate changes.

Table 8: Relative and cumulative frequencies of the fossil fuels_RDF_solving the problem of climate change, $\mathrm{N}=100$.

\begin{tabular}{|l|c|c|}
\hline & Freq & $\%$ \\
\hline 0 & 40 & 40.000 \\
\hline 1 & 26 & 26.000 \\
\hline 2 & 13 & 13.000 \\
\hline 3 & 9 & 9.000 \\
\hline 4 & 12 & 12.000 \\
\hline Total & 100 & 100.00 \\
\hline
\end{tabular}

Legend: 0 - I don't know, I am partially informed; 1 - RDF; 2 - fossil fuels; 3 -gas; 4 - all the fuels are equally harmful.

The frequency analysis for the fossil fuels_RDF_solving the problem of climate changes variable according to the aim groups showed that the representatives of certain subgroups significantly differed in their attitudes. The representatives of the CIT and RES/SOL aim group were least informed, and had little information on the difference in using RDF and fossil fuels. The $E M P / C E M$ and $C O U$ entities were of opinion that RDF was less harmful for the environment. The examinees of the ORG aim group suggested gas as the most acceptable fuel, and $12 \%$ of the total sample considered that all the sources were equally harmful. The frequency results of code answers are shown in table 9.

Table 9: Frequency of the fossil fuels_RDF_solving the problem of climate changes variable, according to the aim group, $\mathrm{N}=100$.

\begin{tabular}{|l|c|c|c|c|c|c|c|c|c|c|}
\hline & ORG & CIT & $\begin{array}{c}\text { BUY/ } \\
\text { SUP }\end{array}$ & $\begin{array}{c}\text { POL/ } \\
\text { SCI }\end{array}$ & $\begin{array}{c}\text { REC.SPO/ } \\
\text { DON }\end{array}$ & $\begin{array}{c}\text { RES/ } \\
\text { KAS }\end{array}$ & $\begin{array}{c}\text { RES/ } \\
\text { SOL }\end{array}$ & $\begin{array}{c}\text { EMP/ } \\
\text { CEM }\end{array}$ & COU & TOTAL \\
\hline 0 & 0 & 9 & 6 & 5 & 4 & 6 & 10 & 0 & 0 & 40 \\
\hline 1 & 0 & 0 & 0 & 5 & 3 & 1 & 0 & 10 & 7 & 26 \\
\hline 2 & 1 & 1 & 0 & 0 & 0 & 6 & 5 & 0 & 0 & 13 \\
\hline 3 & 9 & 0 & 0 & 0 & 0 & 0 & 0 & 0 & 0 & 9 \\
\hline 4 & 0 & 0 & 4 & 0 & 3 & 2 & 0 & 0 & 3 & 12 \\
\hline TOTAL & 10 & 10 & 10 & 10 & 10 & 15 & 15 & 10 & 10 & 100 \\
\hline
\end{tabular}

Legend: 0 - I don't know, I am partially informed; 1 - RDF; 2 - fossil fuels; 3 - gas; 4 all the fuels are equally harmful. 
Table 10 shows the division of the public sector representatives on entities who were of opinion that RDF was the most acceptable fuel regarding the environment, quantitatively defined with 12 examinees or $17 \%$, the entities with the $20 \%$ part who did not offer the answer because they were not well informed, and 3 examinees who considered that the fossil and RDF fuels were equally harmful. Nine examinees from the civil sector suggested gas as a fuel with least influence on climate change. Ten entities of the economy sector were of opinion that RDF was the most acceptable fuel, six entities was not well informed and had no opinion, and four examinees were of opinion that the fossil and RDF fuels equally influenced climate change.

Table 10: Frequency of the fossil fuels_RDF_solving the problem of climate changes variable, according to the sector group, $\mathrm{N}=70$.

\begin{tabular}{|l|c|c|c|c|}
\hline & PUBLIC & CIVIL & ECONOMY & TOTAL \\
\hline 0 & 14 & 4 & 6 & 24 \\
\hline 1 & 12 & 3 & 10 & 25 \\
\hline 2 & 1 & 1 & 0 & 2 \\
\hline 3 & 0 & 9 & 0 & 9 \\
\hline 4 & 3 & 3 & 4 & 10 \\
\hline TOTAL & 30 & 20 & 20 & 70 \\
\hline
\end{tabular}

Legend: 0 - I don't know, I am partially informed; 1 - RDF; 2 - fossil fuels; 3 - gas; 4 - all the fuels are equally harmful.

\section{Conclusions}

Most of the examinees were of opinion that the introduction of fuels made from waste as a substitution for the fossil fuels was conditioned exclusively by profit, financial reasons and the decrease of production expenses.

The rest was divided into two groups according to their attitudes, first group considered that the legal obligations comprising the Kyoto protocol, decrease of greenhouse gases, $\mathrm{CO}_{2}$, and the establishment of the waste management system were the reasons for the introduction of fuels made from waste as a substitution for fossil fuels, while the other group represented the opinion that the reasons for the application of substitution fuels were multiple, comprising the financial decrease of expenses, profit and legal regulations, Kyoto protocol, decrease of greenhouse gases and $\mathrm{CO}_{2}$. The public and civil sector dominantly represented the attitude that the exclusive reasons were profit, while the economy sector was divided. All three sectors confirmed that the examinees within the defined clusters differed in opinions which were the main reasons for the usage of fuels made from waste instead of fossil fuels in cement plants (Pletikosić [3]). Most examinees were of attitude that the Croatian law allowed the usage of substitute fuels made from communal waste in Croatian cement plants. The examinees did not have a clear attitude on the question which fuels - fossil fuels or those made from waste, were less harmful for the environment and climate change. Most of 
the public sector answered that they did not know, were not sure, had little information or were partially acquainted, unlike the economy sector that was of the opinion that fossil fuels were more harmful for the environment and climate change (Pletikosić [4]). The insufficient level of public information and the included participants disables the reaching of the set goals of decreasing the carbon dioxide emission and adjusting to climate change.

\section{References}

[1] Battelle, Toward a Sustainable Cement Industry. An independent study and its substudies, A Report commissioned by the World Business Council on Sustainable Development, WBCSD: Geneva, 2002.

[2] Charmaz K., The grounded theory method: An explication and interpretation. In: Contemporary field research, Emerson RM (ed), Little Brown: Boston; 109-126, 1983.

[3] Pletikosić M., Odnos javnosti prema korištenju zamjenskog goriva u industriji cementa. Magistarski rad. Sveučilište u Zadru, [In Croatian]. [Public attitudes towards the use of alternative fuel in cement industry. Master thesis, University of Zagreb, Zagreb], 2012.

[4] Pletikosic M., Attitude of the Public Towards the Coexistence of Industry and Tourism. MCBE '13 and MCTS '13, Baltimore, MD. 2013, WSEAS Press: USA, 2013. 